\title{
Distribution of the Two Social Forms of the Fire Ant Solenopsis invicta (Hymenoptera: Formicidae) in the Native South American Range
}

\author{
MARK C. MESCHER, ${ }^{1}$ KENNETH G. ROSS, D. DEWAYNE SHOEMAKER, ${ }^{2}$ LAURENT KELLER, $^{3}$ \\ AND MICHAEL J. B. KRIEGER
}

Department of Entomology, University of Georgia, Athens, GA 30602-2603

\begin{abstract}
Ann. Entomol. Soc. Am. 96(6): 810-817 (2003)
ABSTRACT Polygyne (multiple queen) colony social organization in the fire ant Solenopsis invicta Buren is always associated with the presence of a particular class of alleles at the gene Gp-9. We used diagnostic polymerase chain reaction assays capable of distinguishing these alleles to determine the location of polygyne populations in the native South American range of this species. We found that polygyny occurs in a mosaic pattern with respect to the more common monogyne (single queen) social form, a pattern superficially similar to that seen in the introduced range in the United States. However, polygyny appears to be relatively restricted in its geographical prevalence in the native range compared with the introduced range. This difference may stem from higher dispersal rates in the introduced range, which are associated with greater opportunities for human-mediated transport of mated queens or colony fragments. On the basis of our distributional data and results from other studies, the southern part of the native range of S. invicta, particularly northeastern Argentina, is emerging as the most likely geographic source of the founders of the U.S. population.
\end{abstract}

KEY WORDS fire ants, polygyny, social organization, Gp-9, Solenopsis invicta

THE FIRE ANT Solenopsis invicta exhibits two distinct social forms, the monogyne and polygyne forms, that exhibit profound differences in many features of their social and reproductive biology (Ross and Keller 1995). The most notable of these differences is the number of reproductive queens per nest. Monogyne colonies always are headed by a single egg-laying queen, whereas polygyne colonies always contain multiple queens. Because this fundamental difference in colony queen number is paralleled by profound differences in the dispersal and reproductive biologies, S. invicta has become a model organism for evolutionary studies of life histories, breeding systems, and genetic structure (e.g., Bourke and Franks 1995; Ross and Keller 1995; Shoemaker and Ross 1996; Vargo 1996; Ross et al. 1997, 1999; DeHeer et al. 1999; Ross 2001). The distribution of the two social forms of this species is now relatively well known in the United States, where the ant is an invasive pest, because of a number of surveys and comparative studies (e.g., Mirenda and Vinson 1982; Glancey et al. 1987; Ross et al. 1987; Porter et al. 1991, 1997; Porter 1992, 1993; Krieger and Ross 2002; C. J. DeHeer, unpublished

${ }^{1}$ Department of Biology, Pennsylvania State University, University Park, PA 16802.

${ }^{2}$ Department of Entomology, University of Wisconsin, Madison, WI 53706.

${ }^{3}$ Institute of Ecology, University of Lausanne, Lausanne, Switzerland. data). In contrast, although both social forms are known to occur in the native range in South America (Ross et al. 1993, 1996, 1997; Porter et al. 1997), few data are available on the distributions and relative frequency of colonies of each type over this large area. Judging from current information, the monogyne form seems to be the more common and widespread of the two types in both the native and introduced ranges.

Ross and Keller (1998, 2002) demonstrated that social form in S. invicta effectively is determined by the genotypic composition of a colony at a gene called Gp-9. This gene has two alleles in the introduced range, designated $B$ and $b$, the protein products of which are distinguishable on the basis of their different mobilities in electrophoretic gels. In the monogyne form, reproductive queens and workers always have genotype $B B$ at $G p-9$. In the polygyne form, reproductive queens always have genotype $B b$, whereas workers possess any of the three possible genotypes $-B B, B b$, and $b b$. The critical proximate factor determining the social organization of a colony appears to be the presence or absence of the $b$ allele among workers. When a significant proportion of colony workers carry this allele, the entire worker population becomes tolerant of supernumerary queens bearing allele $b$ and the colony expresses the polygyne social phenotype (Keller and Ross 1998, Ross and Keller 2002). 
Krieger and Ross (2002) cloned and sequenced $G p-9$ from numerous specimens of each social form of S. invicta from both the introduced (U.S.) and native ranges. Two coding-region variants corresponding to alleles $B$ and $b$ were found in the introduced range, and the single amino acid substitution responsible for the different electrophoretic mobilities of the allelic proteins was identified (glutamic acid $\rightarrow$ lysine at residue 151). Sequencing of specimens from the native range revealed the presence of the same two variants found in the United States, as well as a third, electrophoretically "cryptic" allele, the protein product of which is indistinguishable from the $B$ allele product on the basis of its gel mobility. This cryptic allele, designated $b^{\prime}$, is more similar to the $b$ allele than to the $B$ allele over its entire coding sequence, yet it bears the same charge-conferring amino acid at position 151 as the $B$ allele (glutamic acid). As predicted on the basis of its overall similarity to the $b$ allele, Krieger and Ross (2002) found the $b^{\prime}$ allele only in ants from polygyne nests. Thus, this study further substantiated the universal association of " $b$-like" alleles with polygyny in $S$. invicta in both the native and introduced ranges.

In the current study, we employ diagnostic polymerase chain reaction (PCR)-based DNA assays capable of distinguishing the three known coding-region variants of $G p-9$ in a first attempt to determine the distribution and relative frequency of monogyny and polygyny in native $S$. invicta populations. The distribution of the social forms in the native range is of interest for several reasons. Given the strong genetic basis to the expression of social organization, description of the frequency and distribution of the alternate forms (and the alleles underlying the expression of social organization) can shed light on patterns of gene flow at varying spatial scales. Also, determination of the locations at which polygyny occurs could lead to identification of ecological factors that favor the presence of this social form, assuming such factors exist, which may in turn help explain the evolutionary maintenance of this balanced social polymorphism. Moreover, the relative abundance of the two forms in the native range should reveal the long-term evolutionary success of the alternative life history and breeding strategies characterizing each. Comparison with distributional patterns in the introduced United States range can then be used to better understand how rapid colonization of a new environment may have altered the ecological and evolutionary balance between the social forms. Finally, knowledge of the distribution of polygyny in the native range may help narrow the list of candidate source populations from which the colonizers of the United States originated.

\section{Materials and Methods}

Sample Collection and DNA Extraction. Solenopsis invicta occupies an extensive native range reaching from southeastern Peru to central Argentina and southern Brazil (Buren et al. 1974, Trager 1991, Pitts 2002). Samples were collected from eight widespread geographic localities spanning much of this range (Fig.
1). Each collection locality is separated from all others by no less than $100 \mathrm{~km}$, and all samples from a single locality were collected within a $50-\mathrm{km}^{2}$ area. Specimens were obtained in one of two ways: newly mated queens were collected on the ground immediately after having completed their mating flights, or individuals were taken directly from nests. In the latter case, several adult workers (females) were collected from each nest, as were winged (virgin) queens when these were available. All samples were frozen immediately in liquid nitrogen in the field and subsequently transferred to an ultra-low temperature freezer $\left(-80^{\circ} \mathrm{C}\right)$ for long-term storage. All samples were identified as S. invicta by James P. Pitts on the basis of their morphological characteristics (Trager 1991, Pitts 2002).

A total of 472 individuals served as the initial material for DNA extraction to assay colony social form at the eight sampling localities (hereafter termed "populations"). A single randomly chosen female from each nest was used; a winged queen was selected if available, otherwise, a worker was chosen. Each individual ant used in the initial round of PCR assays, therefore, is known or can be assumed (in the case of queens from mating flights) to have originated from a separate nest. No fewer than 30 nests, and as many as 84 nests, were assayed from each population in this initial round. For a second round of PCR assays, the DNA of multiple individuals per nest was pooled by bulk extraction (see below). Table 1 lists the material from which DNA was extracted for both rounds of PCR assays, including the sample sizes for each population. All DNA extractions were accomplished with the PUREGENE kit (Gentra Systems, Minneapolis, MN) by following the manufacturer's instructions for extraction from solid tissues. Aliquots $(1 \mu \mathrm{l})$ of the hydrated DNA extracted from all samples were run out in $1 \%$ agarose gels, stained with ethidium bromide, and viewed under ultraviolet light to ensure that a discrete, high-molecular-weight band was apparent. Also, each of the DNA samples from individual ants was used successfully as a template in multiplexed PCR reactions that amplified seven microsatellite loci in a separate study (unpublished data). These procedures confirm that DNA of sufficient quality and quantity to support the PCR assays described below were obtained for each sample.

Diagnosis of Social Form by PCR Assay. The study of Krieger and Ross (2002) showed that polygyny in native $S$. invicta colonies invariably is associated with the presence of either the $b$ or $b^{\prime}$ coding-region variants of $G p-9$, collectively referred to as the " $b$-like" alleles. [Individual polygyne colonies in the native range apparently contain either the $b$ or the $b^{\prime}$ allele, but never both (unpublished data).] In contrast, monogyne colonies contain only homozygotes for the $B$ allele of this gene (Ross 1997, Krieger and Ross 2002). The absolute association of the $b$-like alleles with polygyny means that it is possible to diagnose colony social form by using a PCR assay that detects $b$-like alleles, a task that can be accomplished by employing primers complementary to the $b$-like sequences but 


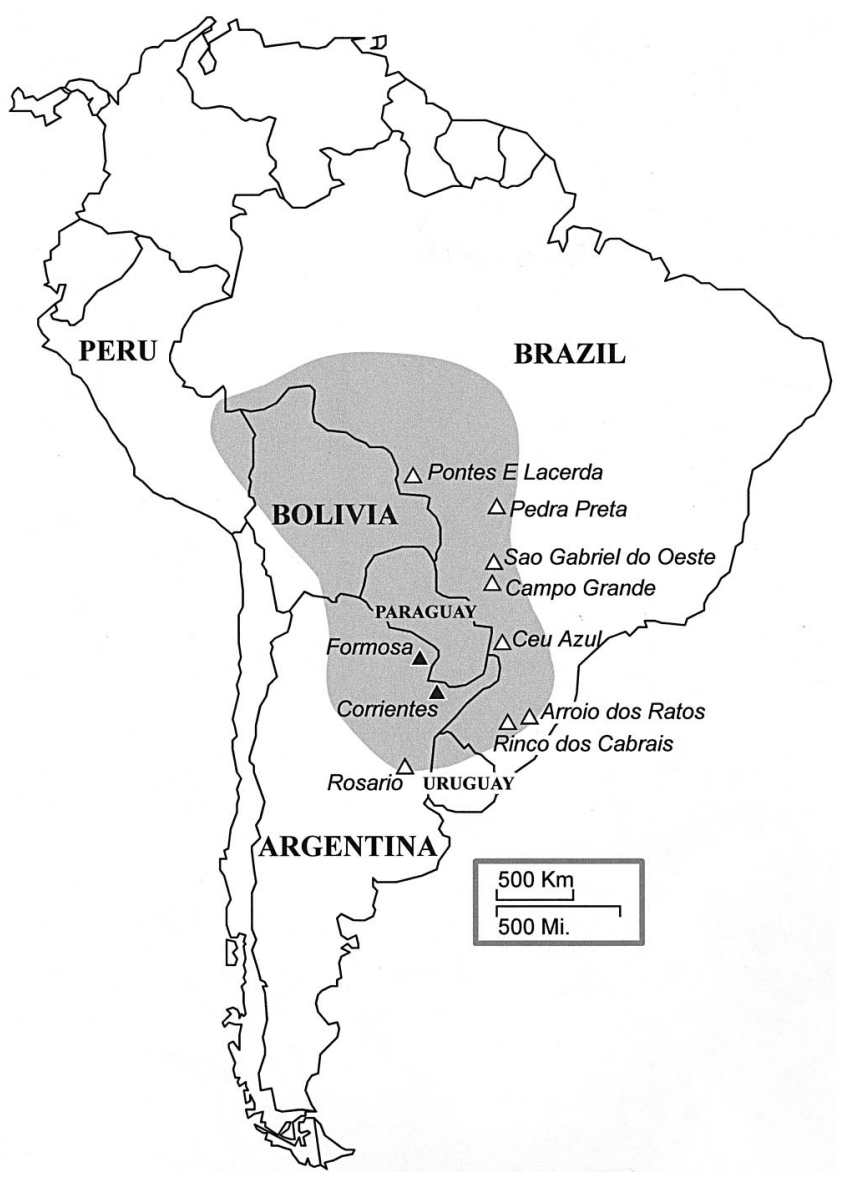

Fig. 1. Locations of populations of native S. invicta from which specimens were collected for determination of social form. White triangles indicate locations of samples for the current study; black triangles indicate locations of samples from the studies of Ross (1997) and Ross et al. (1997). Extent of the native range, indicated by shading, is based on Buren et al. (1974), Trager (1991), and Pitts (2002).

not the $B$ allele sequence. For our study, this diagnostic PCR assay incorporated two forward primers, one fully complementary to the $b$ allele and the other fully complementary to the $b^{\prime}$ allele, and a single reverse primer fully complementary to all three alleles (see Table 2 for primers). PCR reactions were set up in $20-\mu \mathrm{l}$ reaction mixtures containing $1.6 \times \mathrm{PCR}$ buffer (16 mM Tris-HCl, $2.4 \mathrm{mM} \mathrm{MgCl} 2,80 \mathrm{mM} \mathrm{KCl})$, $1 \times$ Q-Solution (Qiagen), $100 \mu \mathrm{M}$ dNTP, $0.167 \mu \mathrm{M}$ of primer Gp9 b.for, $0.333 \mu \mathrm{M}$ of primer Gp9 $b$ prime. for, $0.5 \mu \mathrm{M}$ of primer Gp9 all.rev, $2 \mu \mathrm{l}$ of hydrated template DNA, and $1.0 \mathrm{U}$ of $\bar{T} a q$ DNA polymerase. PCR reactions were conducted in $0.5-\mathrm{ml}$ thin-wall PCR tubes under a mineral oil barrier. The following cycling profile was employed: initial denaturation at $92^{\circ} \mathrm{C}(2 \mathrm{~min}) ; 35$ cycles of $92^{\circ} \mathrm{C}(45 \mathrm{~s}), 57^{\circ} \mathrm{C}$ $(45 \mathrm{~s})$, and $72^{\circ} \mathrm{C}(1 \mathrm{~min})$; and a final elongation step at $72^{\circ} \mathrm{C}(5 \mathrm{~min})$. The predicted $219-\mathrm{bp}$ PCR product in individuals bearing a $b$-like allele was visualized under ultraviolet light in a $2 \%$ agarose gel stained with ethidium bromide. Preliminary experiments using varying concentrations of template DNA from 14 individuals of known genotype confirmed that the assay is robust in that it invariably detected a $b$-like allele in six $B b$ and four $B b^{\prime}$ individuals but yielded no falsepositive results for four $B B$ individuals. For the study samples, positive controls comprising two individuals, one bearing a $b$ and the other a $b^{\prime}$ allele, as well as a negative control comprising a single $B B$ individual, were included in every PCR batch.

This form-diagnostic PCR assay was conducted on each of the 472 S. invicta females from separate nests from which template DNA was individually extracted. For the subset of these individuals in which a $b$-like allele was detected, it can be concluded that the nest of origin was polygyne. However, it is possible that some of the remaining nests not diagnosed as such after this initial round of assays also were polygyne, because nests of this form always contain some proportion of individuals lacking a $b$-like allele (i.e., $B B$ homozygotes). [The proportion of $B B$ homozygotes in polygyne nests has not been well studied in native $S$. invicta, so it is not possible to calculate the probability of nondetection of polygyny (not sampling a worker with a $b$-like allele) when only a single female per nest is assayed. In introduced (U.S.) populations, the pro- 
Table 1. Populations from which native $S$. invicta specimens were collected and material from which DNA was extracted for PCR assays

\begin{tabular}{lc}
\hline \hline Population & Material for DNA extraction/ \\
PCR assays
\end{tabular}

$\mathrm{N}$ is the total number of nests (or newly mated queens) assayed in a population; $n$ indicates the subset of nests for which multiple nestmates were used for bulk DNA extraction (see text).

portion of homozygous $B B$ workers in polygyne nests generally lies in the range $0.26-0.64$ (e.g., Ross and Keller 2002); the proportion of homozygous winged queens typically is much lower and approaches zero as the queens reach sexual maturity and take part in mating flights (e.g., Ross 1997, Keller and Ross 1998, DeHeer et al. 1999).] Thus, further efforts were made to identify polygyne nests by bulk-extracting DNA from 8 to 10 females per nest (queens or workers) and conducting the diagnostic PCR assay on this pooled DNA. The number of nests in each population assayed in this second round using bulk-extracted DNA is detailed below.

To determine the sensitivity of the diagnostic PCR assay when applied to pooled DNA, especially in situations in which individuals with $b$-like alleles constitute a minority of the nestmates in a bulk DNA extraction, an experiment was conducted in which template DNA from individuals of known Gp-9 genotype was mixed in the following ratios (by volume): 1 $B b: 1 \mathrm{BB}, 1 \mathrm{Bb}: 2 \mathrm{BB}, 1 \mathrm{Bb}: 3 \mathrm{BB}, 1 \mathrm{Bb}: 4 \mathrm{BB}, 1 \mathrm{Bb}: 5 \mathrm{BB}, 1$ $B b: 6 \mathrm{BB}, 1 \mathrm{Bb}: 8 \mathrm{BB}, 1 \mathrm{Bb}: 10 \mathrm{BB}$, and $1 \mathrm{Bb}: 12 \mathrm{BB}$; as well as $1 B b^{\prime}: 4 B B$ and $1 B b^{\prime}: 12 B B$ (different individuals were used as the source of DNA for each ratio). For each one of these mixed templates, the PCR assay yielded the diagnostic 219-bp amplification product from a $b$-like allele. This means that the technique is very sensitive at detecting $b$-like alleles in the DNA pools of nestmates, and thus that this assay can be highly effective in diagnosing polygyny in a colony when coupled with bulk DNA extraction.

Determination of the Identity of $b$-like Alleles in Polygyne Nests. To determine which of the two $b$-like alleles, $b$ or $b^{\prime}$, was present in each confirmed polygyne nest, a second, $b^{\prime}$-allele-specific, PCR assay was developed. This assay took advantage of a single nucleotide difference between the two alleles in the region of the $G p-9$ sequence bound by the forward primers (see Table 2) to achieve selective amplification of the $b^{\prime}$ allele. PCR reactions for this assay were set up in $20-\mu$ l reaction mixtures containing $1 \times$ PCR buffer (10 mM Tris-HCl, $1.5 \mathrm{mM} \mathrm{MgCl}{ }_{2}, 50 \mathrm{mM} \mathrm{KCl}$ ), $1 \times$ Q-Solution, $100 \mu \mathrm{M}$ dNTPs, $0.5 \mu \mathrm{M}$ of each primer Gp9_b_prime.for and Gp9_all.rev, $2 \mu \mathrm{l}$ of template DNA $\bar{A}$, and $1.0 \mathrm{U}$ of Taq DNA polymerase. PCR reactions were performed in the same way as for the diagnostic assay for social form, but with the annealing temperature raised to $65^{\circ} \mathrm{C}$. The sensitivity and selectivity of this assay were demonstrated by using it on DNA extracted from four $B b$, four $B b^{\prime}$, and two $B B$ individuals for which $G p-9$ sequences were obtained by Krieger and Ross (2002); the 219-bp product was only detected in the $B b^{\prime}$ individuals. For the study samples, a positive control comprising an individual known to bear a $b^{\prime}$ allele and a negative control comprising an individual with a $b$ allele were included in every PCR batch. The $b^{\prime}$-allele-specific PCR assay was conducted on all individual or bulked (nest) DNA samples for which $b$-like alleles had been previously detected.

\section{Results}

Of the 472 individuals subjected to the first round of diagnostic PCR assays for a $b$-like allele, only eleven were found to possess such an allele indicative of polygyny in their nest of origin. These individuals came from just two of the eight study populations, Arroio dos Ratos (6 of 44 [13.6\%] individuals) and Campo Grande (5 of 43 [11.6\%] newly mated queens). The remaining six populations appeared to contain only the monogyne form, based on the absence of

Table 2. Primers used in PCR assays to detect Gp-9 alleles in S. invicto

\begin{tabular}{|c|c|c|}
\hline Primer name & Primer sequence & $\begin{array}{c}\text { Position of } 5^{\prime} \\
\text { nucleotide }\end{array}$ \\
\hline \multicolumn{3}{|l|}{ Forward primers: } \\
\hline Gp9_b.for & 5'-TCGCCGATTCTAACAAAGCT-3' & 1677 \\
\hline Gp $9 \_b$ prime.for & 5'-TCGCCGATTCTAACGAAGCT-3' & 1677 \\
\hline \multicolumn{3}{|l|}{ Reverse primer: } \\
\hline Gp9 all.rev & 5'-AATGAAGAAATTGATAATTCTGATCC-3' & 1895 \\
\hline
\end{tabular}

The position of the $5^{\prime}$ nucleotide is indicated with respect to the start codon in the $S$. invicta $G p$ - 9 sequences deposited in GenBank $(b$ allele: AF427898; $b^{\prime}$ allele: AF4279008). The primer Gp $9 \_b$.for is fully complementary to the $b$ allele, the primer $G p 9 \_b \_p r i m e . f o r$ is fully complementary to the $b^{\prime}$ allele, and the primer Gp 9 all.rev is fully complementary to all known Gp-9 alleles in S. invicta. 
$b$-like alleles among the substantial numbers of individuals (nests) sampled from each location.

Because individuals lacking $b$-like alleles occur in polygyne nests, it is possible that some sampled polygyne nests were not recognized as such when the PCR assay was applied to only a single resident. Therefore, the second round of form-diagnostic PCR assays was applied to bulk-extracted DNA of multiple nestmate females from a subset of nests selected as follows. For the six populations in which no single individuals were found to possess a $b$-like allele in the first round, ten nests were randomly selected for bulk-extraction of DNA. For the Arroio dos Ratos population, every nest not initially diagnosed as polygyne ( $N=38$ nests) was selected. For the Campo Grande population, the two nests represented by sample material collected directly from the nest were selected.

Only 2 of the 100 nests from which DNA was bulkextracted and used in the PCR assay for a $b$-like allele were found to possess such an allele indicative of polygyny. Both of these nests were from Arroio dos Ratos, one of the two populations previously confirmed to contain polygyne nests. Thus, 8 nests of 44 $(18.2 \%)$ in this population ultimately were determined to be polygyne. The complete absence of $b$-like alleles in the bulk-extracted and individual DNA samples from six of the eight study populations indicates that these populations are likely to consist solely of monogyne colonies.

To determine whether the 13 colonies determined to be polygyne in the preceding steps possessed the $b$ or the $b^{\prime}$ allele [individual polygyne colonies in the native range apparently contain either the $b$ or the $b^{\prime}$ allele, but never both (unpublished data) ], we applied our $b^{\prime}$-allele-specific PCR assay to the individual or bulk-extracted DNA from these colonies. None of the samples yielded a 219-bp amplification product. From this we conclude that polygyny in the Arroio dos Ratos and Campo Grande populations is associated with the presence of the $b$ allele rather than the $b^{\prime}$ allele of Gp-9.

Data collected from earlier studies of two populations in northern Argentina, located near the cities of Formosa and Corrientes (see Fig. 1), supplement the results presented above. On the basis of colony genotype composition at numerous allozyme loci, polygyny was found to be common in both populations (Ross 1997, Ross et al. 1997). Among the polygyne nests discovered, roughly one half in each population were shown to possess the $b$ allele, whereas the remainder were shown or inferred to possess the $b^{\prime}$ allele (K.G.R., unpublished data). To confirm the common occurrence of the $b^{\prime}$ allele in polygyne nests from these two populations, we bulk-extracted DNA from 8 to 10 females from all polygyne nests in each population suspected of containing the $b^{\prime}$ allele based on their $G p-9$ protein electrophoretic banding profiles (individuals in these polygyne nests displayed only bands with the mobility of the $b^{\prime}$ and $B$ allele products). These bulk samples then were subjected to our $b^{\prime}$-allele-specific PCR assay. A 219-bp amplification product was detected in 13 of 14 candidate samples from Formosa and 18 of 20 candidate samples from Corrientes, confirming the common occurrence of the $b^{\prime}$ allele in these polygyne $S$. invicta populations from northern Argentina.

\section{Discussion}

We used a PCR assay diagnostic for alleles associated with polygyny in S. invicta to determine the location of colonies with this form of social organization in the native South American range of the species. Our study, combined with the results of earlier surveys for polygyny (Porter et al. 1997, Ross 1997, Ross et al. 1997, Krieger and Ross 2002), leads to several important conclusions. First, polygyny exhibits a mosaic distribution in the native range with respect to the occurrence of the more common, alternate social form, monogyny (see Fig. 2). That is, polygyny is not confined to a specific, definable part of the range in which it occurs to the exclusion of monogyny. Rather, isolated patches of polygyny occur in several different, widespread localities that are separated from one another by intervening monogyne populations, a pattern superficially similar to that seen in the United States (e.g., Ross et al., 1987; Porter et al. 1991, 1997; Porter 1992; Krieger and Ross 2002). This finding suggests that the large-scale climatic, ecological, or habitat characteristics distinguishing different regions are not likely to favor the persistence of one form over the other in a given area, a conclusion reinforced by the co-occurrence of both forms at all four native sites at which we have detected polygyny (see also Ross and Keller 1995). The distribution of each form across the native range may instead primarily reflect the historical, and to a large extent stochastic, processes of colonization and population extinction.

However, polygyny does appear to be relatively restricted in its geographical occurrence in the native range in comparison to the introduced range (Fig. 2); this form was found only in the south-central portion of the native range, whereas it occurs quite commonly in virtually all areas of the introduced range. A caveat in this comparison is that greater effort undoubtedly has been given to surveying colony social form in the United States, because of the economic importance of invasive S. invicta. Nonetheless, we searched exhaustively for polygyny along a $>1500-\mathrm{km}$ transect between Pontes E Lacerda and Ceu Azul in east-central Brazil using diagnostic field criteria (Greenberg et al. 1985, Porter et al. 1991, Porter 1992) in conjunction with our PCR assays, yet we were able to identify this social form only in the Campo Grande population. Thus, we are confident in our conclusion that polygyny has a more restricted geographical distribution in the native range than in the introduced range.

This difference in the prevalence of polygyny across the two ranges may be explained if dispersal rates are higher in the introduced range than in the native range, especially for the polygyne form, which seems to have quite limited natural dispersal (see below). High levels of dispersal lead to a more rapid spread of populations from their point of origin or introduction which, in the case of S. invicta, should eventually 

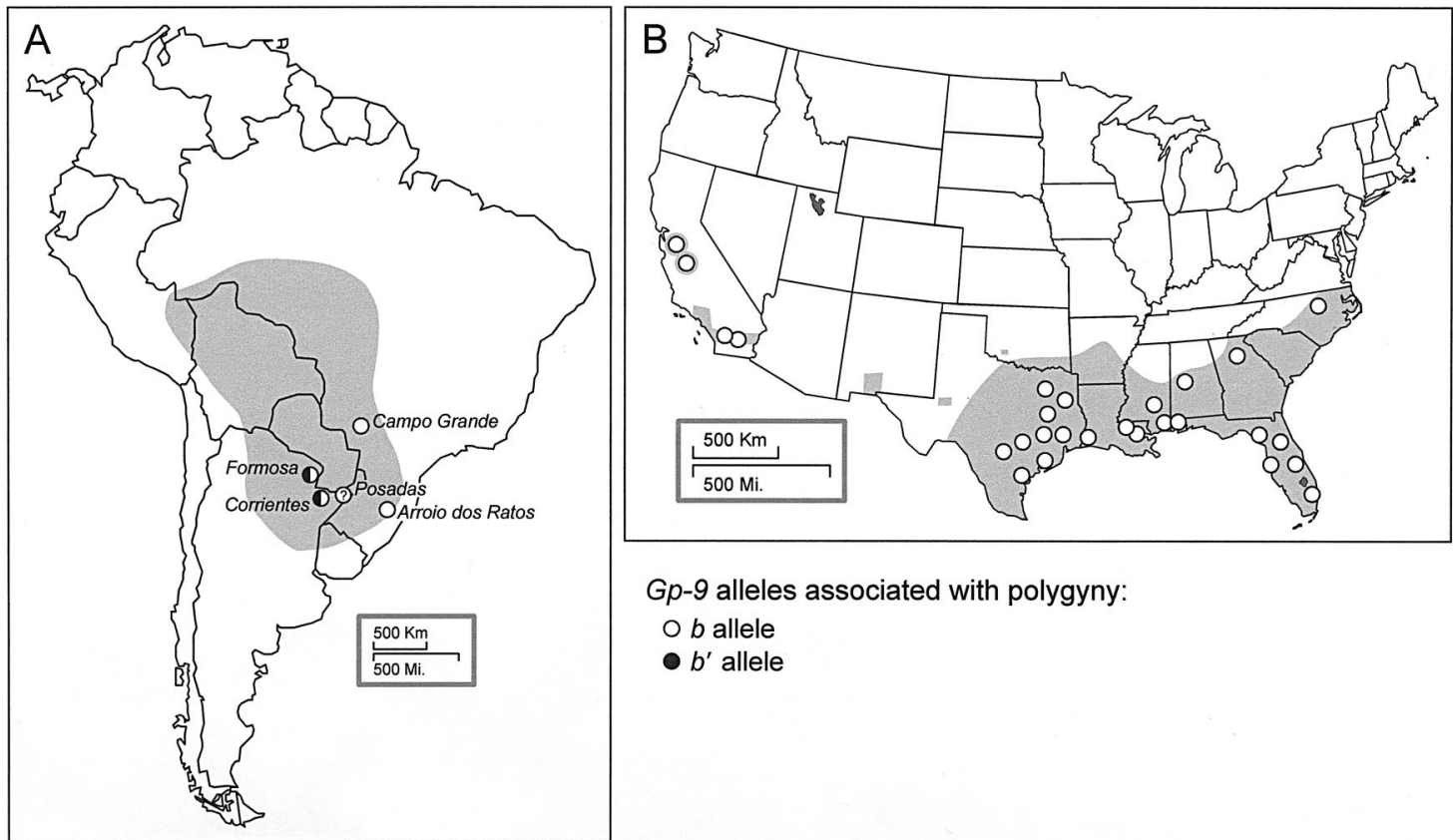

\section{Gp-9 alleles associated with polygyny: $\circ b$ allele \\ - $b^{\prime}$ allele}

Fig. 2. Locations of reported polygyne populations of S. invicta (circles): (A) in native range; (B) in introduced (U.S.) range. Known ranges are indicated by shading. The identity of the specific $b$-like allele of Gp- 9 associated with polygyny in each population is shown (the identity of the $b$-like allele(s) underlying polygyny in the Posadas, Argentina population is unknown [Porter et al 1997]). Only the $b$ allele has been found in the polygyne form in the United States. Extent of the introduced range is based on a USDA-APHIS quarantine map from February, 2003 published at www.aphis.usda.gov/ppq/ maps / fireant.pdf (the distributions of S. richteri and hybrid S. invicta/richteri are excluded from this map; these are reported in Diffie et al. [1988] and Shoemaker [1994]). Data in (A) are from Porter et al. (1997), Ross (1997), Ross et al. (1997), Krieger and Ross (2002), and this study. Data in (B) are from Glancey et al. (1987), Ross et al. (1987), Porter et al. (1991, 1997), Porter (1992), Krieger and Ross (2002), C. J. DeHeer (unpublished data), and K.G.R. (unpublished data).

create more or less concordant distributions of the two social forms, similar to what is seen in the United States (Fig. 2). Population densities of fire ants are much higher in the United States than in South America (Porter et al. 1992, 1997), as are the overall densities of humans and their vehicles in the relevant areas. Consequently, there are improved opportunities for transport of mated queens, colonies, or colony fragments by human agency in the United States, consistent with artificially elevated dispersal rates in the introduced range. Transport of colony fragments apparently is an especially important means of spread of the polygyne form, because each fragment that contains a mated queen is a potential founder; this presumably explains the appearance of polygyne colonies in some areas that are well separated from the main body of the range in the United States (e.g., Fletcher 1983; see also Fig. 2).

Earlier population genetic data based on numerous nuclear and mtDNA markers support two important elements in this scenario. First, these data reveal far lower regional genetic differentiation in the introduced range than in the native range, consistent with the idea that dispersal at this large scale is far more extensive in introduced than in native fire ants, regardless of social form (Ross et al. 1997, 1999; Ross and Shoemaker 1997). Second, local genetic differentia- tion is significant (and pronounced in the case of the mtDNA) in native polygyne populations (Ross et al. 1997, Ross 2001), the likely result of very low queen vagility in this form under natural conditions. The extremely localized occurrence of the polygyny-inducing $b^{\prime}$ allele in northeastern Argentina documented in this study (Fig. 2) further supports the conclusion that gene flow in native polygyne fire ants normally is quite limited, a conclusion made all the more compelling by the fact that the $b^{\prime}$ allele is likely to be the ancestral polygyny-inducing allele in S. invicta (Krieger and Ross 2002).

In aggregate, the information from these various sources suggests that the evolutionary balance between the social forms of S. invicta in the native range, in which polygyne populations are relatively rare and geographically restricted, has been disrupted in the United States because of artificially induced (anthropogenic) increases in dispersal rates. The increased dispersal is likely to have had an inordinate impact on the distribution of the polygyne form in its new range because of the naturally limited dispersal abilities characterizing this form (Ross and Keller 1995, Ross 2001). The increase in dispersal may in turn be traced to the elevated population densities of these ants in the introduced range, a likely consequence of abundant disturbed habitats suitable for colonization as well as 
ecological release from natural enemies and competitors that normally regulate fire ant abundance (see Porter et al. 1992, 1997).

An alternative explanation for the difference in prevalence of polygyny between the native and introduced ranges invokes intercontinental differences in biotic or abiotic factors that favor one form over the other. As an example, predators or parasites that specialize on polygyne nests (e.g., the microsporidium Thelohania solenopsae; Williams et al. 1998) may be more prevalent in the native than the introduced range. In such a case, disruption of the evolutionary balance between the forms again can be traced to the introduction event and its biotic consequences.

Finally, the data we present here provide new insights regarding the likely source population(s) of $S$. invicta from which the U.S. colonizers originated. Given that some colonizers must have carried $b$-like alleles to the United States, the source population in all likelihood is located in the southern half of the native range. All four of the polygyne populations we have studied carry the $b$ allele, the only $b$-like allele found in the polygyne form in the United States, and polygyne populations from Argentina carry the $b^{\prime}$ allele as well. Although this may suggest that northeastern Argentina is somewhat less likely than southeastern Brazil to be a source of the colonists, data from morphological characters (Trager 1991), allozyme loci (Ross and Trager 1990), and mtDNA sequences (Ross et al. 1997; D.D.S., unpublished data) provide evidence that northeastern Argentina is, in fact, the most likely candidate region to have served as a source of the U.S. colonists. Ongoing studies using multiple markers of nuclear and organellar DNA in native $S$. invicta will help further resolve this issue.

\section{Acknowledgments}

We thank Erin Cox and Ben Goins for assistance in the laboratory, and James Pitts for assistance in the field and identification of specimens. This study was funded by K. G. Ross and by grants from the College of Agriculture and Life Sciences at the University of Wisconsin, the Georgia Agricultural Experiment Stations (University of Georgia), the National Geographic Society, the Swiss National Science Foundation, the United States Department of Agriculture NRICGP, and the U.S. National Science Foundation.

\section{References Cited}

Bourke, A.F.G., and N. R. Franks. 1995. Social evolution in ants. Princeton University Press, Princeton, NJ.

Buren, W. F., G. F. Allen, W. H. Whitcomb, F. E. Lennartz, and R.N. Williams. 1974. Zoogeography of the imported fire ants. J. New York Entomol. Soc. 82: 113-124.

DeHeer, C. J., M.A.D. Goodisman, and K. G. Ross. 1999. Queen dispersal strategies in the multiple-queen form of the fire ant Solenopsis invicta. Am. Nat. 153: 660-675.

Diffie, S., R. K. Vander Meer, and M. H. Bass. 1988. Discovery of hybrid fire ant populations in Georgia and Alabama. J. Entomol. Sci. 23: 187-191.

Fletcher, D.J.C. 1983. Three newly-discovered polygynous populations of the fire ant, Solenopsis invicta, and their significance. J. Ga. Entomol. Soc. 18: 538-543.
Glancey, B. M., J.C.E. Nickerson, D. Wojcik, J. Trager, W. A. Banks, and C. T. Adams. 1987. The increasing incidence of the polygynous form of the red imported fire ant, Solenopsis invicta (Hymenoptera: Formicidae), in Florida. Fla. Entomol. 70: 400-402.

Greenberg, L., D.J.C. Fletcher, and S. B. Vinson. 1985. Differences in worker size and mound distribution in monogynous and polygynous colonies of the fire ant Solenopsis invicta Buren. J. Kans. Entomol. Soc. 58: 9-18.

Keller, L., and K. G. Ross. 1998. Selfish genes: a green beard in the red fire ant. Nature (Lond.) 394: 573-575.

Krieger, M.J.B., and K. G. Ross. 2002. Identification of a major gene regulating complex social behavior. Science 295: $328-332$.

Mirenda, J. T., and S. B. Vinson. 1982. Single and multiple queen colonies of imported fire ants in Texas. Southwest. Entomol. 7: 135-141.

Pitts, J. P. 2002. A cladistic analysis of the Solenopsis saevissima species-group (Hymenoptera: Formicidae). PhD dissertation, University of Georgia, Athens, GA.

Porter, S. D. 1992. Frequency and distribution of polygyne fire ants (Hymenoptera: Formicidae) in Florida. Fla. Entomol. 75: 248-257.

Porter, S. D. 1993. Stability of polygyne and monogyne fire ant populations (Hymenoptera: Formicidae: Solenopsis invicta) in the United States. J. Econ. Entomol. 86: 13441347.

Porter, S. D., A. P. Bhatkar, R. Mulder, S. B. Vinson, and D. J. Clair. 1991. Distribution and density of polygyne fire ants (Hymenoptera: Formicidae) in Texas. J. Econ. Entomol. 84: 866-874.

Porter, S. D., Fowler, H. G., and W. P. MacKay. 1992. Fire ant mound densities in the United States and Brazil (Hymenoptera: Formicidae). J. Econ. Entomol. 85: 11541161

Porter, S. D., D. F. Williams, R. S. Patterson, and H. G. Fowler. 1997. Intercontinental differences in the abundance of Solenopsis fire ants (Hymenoptera: Formicidae): escape from natural enemies? Env. Entomol 26: 373-384.

Ross, K. G. 1997. Multilocus evolution in fire ants: effects of selection, gene flow, and recombination. Genetics 145: 961-974

Ross, K. G. 2001. How to measure dispersal: the genetic approach. The example of fire ants, pp. 29-42. In J. Clobert, E. Danchin, A. A. Dhondt, and J. D. Nichols [eds.], Dispersal. Oxford University Press, Oxford, United Kingdom.

Ross, K. G., and L. Keller. 1995. Ecology and evolution of social organization: insights from fire ants and other highly eusocial insects. Annu. Rev. Ecol. Syst. 26: 631-656.

Ross, K. G., and L. Keller. 1998. Genetic control of social organization in an ant. Proc. Nat. Acad. Sci. U.S.A. 95: 14232-14237.

Ross, K. G., and L. Keller. 2002. Experimental conversion of colony social organization by manipulation of worker genotype composition in fire ants (Solenopsis invicta). Behav. Ecol. Sociobiol. 51: 287-295.

Ross, K. G., and D. D. Shoemaker. 1997. Nuclear and mitochondrial genetic structure in two social forms of the fire ant Solenopsis invicta: insights into transitions to an alternate social organization. Heredity 78: 590-602.

Ross, K. G., and J. C. Trager. 1990. Systematics and population genetics of fire ants (Solenopsis saevissima complex) from Argentina. Evolution 4: 2113-2134.

Ross, K. G., E. L. Vargo, and D.J.C. Fletcher. 1987. Comparative biochemical genetics of three fire ant species in North America with special reference to the two social 
forms of Solenopsis invicta (Hymenoptera: Formicidae). Evolution 41: 979-990.

Ross, K. G., E. L. Vargo, L. Keller, and J. C. Trager. 1993. Effect of a founder event on variation in the genetic sex-determining system of the fire ant Solenopsis invicta. Genetics 135: 843-854.

Ross, K. G., E. L. Vargo, and L. Keller. 1996. Social evolution in a new environment: the case of introduced fire ants. Proc. Nat. Acad. Sci. U.S.A. 93: 3021-3025.

Ross, K. G., M.J.B. Krieger, D. D. Shoemaker, E. L. Vargo, and L. Keller. 1997. Hierarchical analysis of genetic structure in native fire ant populations: results from three classes of molecular markers. Genetics 147: 643655.

Ross, K. G., D. D. Shoemaker, M.J.B. Krieger, C. J. DeHeer, and L. Keller. 1999. Assessing genetic structure with multiple classes of molecular markers: A case study involving the introduced fire ant Solenopsis invicta. Mol. Biol. Evol. 16: 525-543.
Shoemaker, D. D., and K. G. Ross. 1996. Effects of social organization on gene flow in the fire ant Solenopsis invicta. Nature (Lond.) 383: 613-616.

Shoemaker, D. D., K. G. Ross, and M. L. Arnold. 1994. Development of RAPD markers in two introduced fire ants, Solenopsis invicta and S. richteri, and their application to the study of a hybrid zone. Mol. Ecol. 3: 531-539.

Trager, J. C. 1991. A revision of the fire ants, Solenopsis geminata group (Hymenoptera: Formicidae: Myrmicinae). J. NY Entomol. Soc. 99: 141-198.

Vargo, E. L. 1996. Sex investment ratios in monogyne and polygyne populations in the fire ant Solenopsis invicta. J. Evol. Biol. 9: 783-802.

Williams, D. F., G. J. Knue, and J. J. Becnel. 1998. Discovery of Thelohania solenopsae from the Red Imported Fire Ant, Solenopsis invicta, in the United States. J. Invertebr. Pathol. 71: 175-176.

Received for publication 22 November 2002; accepted 22 July 2003. 